\title{
Direct control service from residential heat pump aggregation with specified payback
}

\author{
E. Georges, V. Lemort \\ Thermodynamics Laboratory \\ University of Liège \\ Liège, Belgium
}

\author{
B. Cornélusse, D. Ernst, Q. Louveaux, S. Mathieu \\ Department of Electrical Engineering and Computer Science \\ University of Liège \\ Liège, Belgium
}

\begin{abstract}
This paper addresses the problem of an aggregator controlling residential heat pumps to offer a direct control flexibility service. The service is defined by a 15 minute power modulation, upward or downward, followed by a payback of one hour and 15 minutes. The service modulation is relative to an optimized baseline that minimizes the energy costs. The potential amount of modulable power and the payback effect are computed by solving mixed integer linear problems. Within these problems, the building thermal behavior is modeled by an equivalent thermal network made of resistances and lumped capacitances whose parameters are identified from validated models. Simulations are performed on $\mathbf{1 0 0}$ freestanding houses. For an average $4.3 \mathrm{~kW}$ heat pump, results show a potential of $1.2 \mathrm{~kW}$ upward modulation with a payback of $600 \mathrm{Wh}$ and 150 Wh of overconsumption. A downward modulation of $500 \mathrm{~W}$ per house can be achieved with a payback of 420 Wh and 120 Wh of overconsumption.
\end{abstract}

Index Terms-Heat pumps, Linear programming, Load management, Load modeling, Optimization methods, Power systems

\section{NOMENCLATURE}

This section defines the main symbols used in this paper. Others are defined as required in the text.

\section{Parameters}

$H \quad$ Number of periods in the horizon

$\mathcal{H}$ Optimization horizon $\{1, \ldots, H\}$

$k \quad$ Number of payback periods

$\mathcal{K}(\tau, k) \quad$ Payback horizon $\{\tau, \ldots, \tau+k\}$

$\mathbf{A}^{i}, \mathbf{B}^{i}, \mathbf{E}^{i} \quad$ Parameters of state-space model

$C \quad$ Thermal capacitance

$c_{i}, d_{i}, f_{i} \quad$ Parameters of the heat pump model

$d t$

$C O P_{t} \quad$ Heat pump coefficient of performance

$\epsilon \quad$ Penalty for the payback imbalance

$\Gamma_{t} \quad$ Exogenous power consumed

$Q_{t}^{g}, Q_{t}^{\text {sol }} \quad$ Internal heat gains, solar gains

$\pi_{t}^{+} \quad$ Buying price of electricity

$\pi_{t}^{-} \quad$ Selling price of electricity

F.R.S-FNRS is gratefully thanked for funding Research Fellow Emeline Georges. This research is supported by the public service of Wallonia within the framework of the GREDOR project. The authors would also like to acknowledge their collaboration with the FLEXIPAC project consortium.
$R$

$\sigma$

$T_{t}^{a}$

$T_{t}^{s u}$

$\mathbf{u}_{t}$

$\mathbf{x}^{i}$

Variables

$\delta_{t}$

$I^{+}$

$I^{-}$

$P_{t}$

$P_{t}^{+}$

$P_{t}^{-}$

$Q_{t}$

$T_{t}$

$W_{t}$

$\mathbf{x}_{t}$

$y_{t}$

Powers are taken as positive when consumed and negative when produced. A positive modulation corresponds to an increase in consumption. Variables obtained for the baseline are denoted with a $\hat{\bullet}$.

$\begin{array}{ll}\text { Superscripts } & \\ g & \text { gain } \\ \text { sol } & \text { solar } \\ n & \text { nominal } \\ a & \text { ambient } \\ w & \text { water } \\ s u & \text { supply } \\ s & \text { space heating }\end{array}$

\section{INTRODUCTION}

The increase in decentralized power generation and the integration of intermittent renewable energy sources in electrical distribution systems have entailed a rising interest in the use of load modulation services. These services are provided by load aggregators that manage and trade the demand flexibility of electricity consumers. Heat pumps are among the most promising devices to offer flexibility. This study takes the point of view of a load aggregator controlling domestic heat 
pumps and that is willing to offer flexible direct control service. The service consists of an upward or a downward modulation for one time period followed by a fixed number of periods, called payback time, corresponding to the time needed for the system to go back to its baseline state. The amplitudes of the modulations and of the payback are well defined within the service. The maximum power modulation amplitude that can be achieved for a given time period is determined from an optimized baseline. The service could be used by an electricity retailer to balance itself as a balance responsible party. A distribution system operator could resort to this service to relieve a congestion in a line or a transformer [1]. A transmission system operator could rely on this service for its secondary reserve [2], [3].

Among the available flexible loads, thermostatically controlled loads (TCLs) have been shown to present suitable characteristics to perform load following [4]. The following studies focus on detailed demand side models with TCLs. A methodology to build detailed and verified aggregated models to study demand-side management for a cluster of houses equipped with heat pumps is proposed in [5]. Article [6] presents validated physics-based thermal models of residential buildings and equipment with direct energy consumption minimization. Article [7] investigates the potential of using the thermal mass of office buildings to minimize peak demand. A day-ahead multi-objective optimization is implemented to provide the modulation service at minimum cost for the enduser and minimum frequency regulation cost. The optimization also determines the optimal time period to activate the load modulation. The study is extended to a portfolio of office buildings in [8] and the possible additional benefits retrieved from synergies between the buildings are outlined. De Coninck and Helsen [9] develop a bottom-up approach to determine the flexibility of buildings and heating, cooling and air-conditioning systems. Three optimal control problems are solved to determine, first, a cost-optimal baseline for the consumer, and then the maximum upward and downward modulations available during a given time span of the day. Article [10] proposes a similar optimization scheme to [9] that is applied to residential demand response. The costoptimal day-ahead prediction of the baseline is followed by an intraday modulation with the introduction of "bonus" price incentives. A sensitivity study of the percentage of storage capacity allocated respectively to the day-ahead and to the intra-day optimizations is carried out.

In light of the literature review, the first contribution of this paper lies in the investigation of a flexibility service with detailed models of thermostatically controlled loads. The second contribution is the characterization of the payback following the activation of the upward and downward power modulation service and of its influence on the achievable modulation amplitude for different periods of the day. The methodology is therefore complementary to the methods presented in [9] and [10] by constraining the payback time and characterizing the rebound effect in terms of costs and energy volumes, and it differs from [7] in which the payback time is a result of the optimization scheme with a unique daily value.

The paper is organized as follows. Section II defines the flexibility services. The amplitude of modulations are obtained by solving two optimization problems presented in Section III. These optimization problems are based on a thermal model described in Section IV. In Section V, the methodology is applied to an academic case study composed of a hundred buildings. Finally, Section VI concludes the study.

\section{FLEXIBILITY SERVICE}

The product considered in this paper is a flexibility service with a modulation in a given period $\tau$ and payback in $k$ following periods. A graphical representation is provided in Fig. 1. The objective of the aggregator is to obtain the maximum modulation $\delta_{\tau}$, which is positive for an upward modulation and negative for a downward modulation, with the minimum payback in the following $k$ periods.

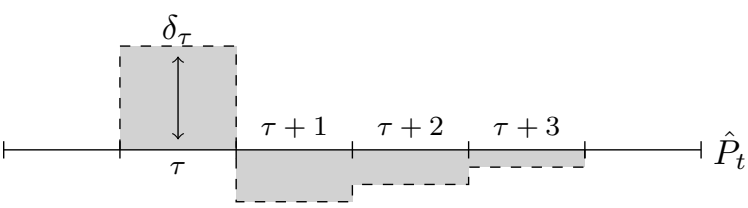

(a) Modution signal.

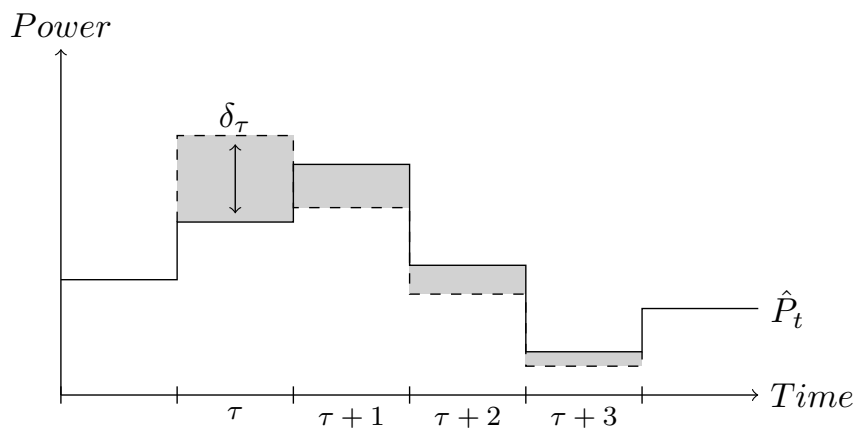

(b) Modulation added to the baseline.

Figure 1: Example of upward modulation with three payback periods.

A modulation must be defined relative to a reference consumption pattern [11]. In this article, we take as reference a baseline $\hat{P}_{t}$ that minimizes the electricity cost for the consumer [12]. This choice has two motivations. First, the use of flexible heat pumps should benefit the end-user. Minimizing the energy cost appears to be a good incentive for consumers to enroll in the flexibility programs proposed by the aggregators. The second motivation lies in the possibility for an aggregator to be a balance responsible party, which compels it to state its positions to the transmission system operator in the form of baselines. In this work, these baselines are computed by the aggregator and used as references to quantify the power modulations and resulting imbalances.

The flexibility service considered here is the result of the aggregation of a set of houses equipped with heat pumps. A typical case is an electricity retailer using the flexibility of its clients to balance its own portfolio as a balance responsible 
party. Another example is an aggregator proposing its services to a distribution system operator willing to relieve a congestion in a line or a transformer or to a transmission system operator for its secondary reserve. The aggregator proposes the service detailed in this section to another actor. The actual volume activated by the other actor, less than or equal to the total potential, is application dependent and is out of the scope of this paper. The service provides all necessary information: the available potential of flexibility and the cost and deviations entailed by the activation of the service. With this information, the other actor is able to make a decision without having to directly manage each individual heat pump.

\section{OPTIMIZATION PROBLEMS}

In this section, the thermal states transition model and the state constraints are summarized by

$$
\begin{aligned}
& \mathbf{x}_{t+1}=f\left(\mathbf{x}_{t}, W_{t}^{s}, W_{t}^{w}, \mathbf{u}_{t}\right) \\
& \mathbf{x}_{t}^{\text {min }} \leq \mathbf{x}_{t} \leq \mathbf{x}_{t}^{\max }
\end{aligned}
$$

The details of this model are given in Section IV. The variables $\mathbf{x}_{t}, W_{t}^{s}$ and $W_{t}^{w}$ are the vector of the state variables, the heat pump consumption for space heating and for domestic hot water heating, respectively. $\mathbf{u}_{t}$ represents the set of timedependent input parameters of the building model.

The first unknown obtained is a base profile that minimizes the energy costs of the heat pump's owner. This base profile is denoted $\hat{P}_{t}$ and the corresponding states are denoted $\hat{\mathbf{x}}_{t}$. They are obtained by solving the following optimization problem for each house.

$$
\min \sum_{t \in \mathcal{H}}\left(\pi_{t}^{+} P_{t}^{+}-\pi_{t}^{-} P_{t}^{-}\right) d t
$$

subject to,

$$
\begin{array}{ll}
\hat{P}_{t}=P_{t}^{+}-P_{t}^{-} & \forall t \in \mathcal{H} \\
\hat{P}_{t}=\hat{W}_{t}^{s}+\hat{W}_{t}^{w}+\Gamma_{t} & \forall t \in \mathcal{H} \\
\hat{\mathbf{x}}_{t+1}=f\left(\hat{\mathbf{x}}_{t}, \hat{W}_{t}^{s}, \hat{W}_{t}^{w}, \mathbf{u}_{\mathbf{t}}\right) & \forall t \in \mathcal{H} \\
\mathbf{x}_{t}^{\text {min }} \leq \hat{\mathbf{x}}_{t} \leq \mathbf{x}_{t}^{\max } & \forall t \in \mathcal{H} \\
0 \leq \hat{W}_{t}^{s} \leq \hat{y}_{t} W_{t}^{s, \max } & \forall t \in \mathcal{H} \\
0 \leq \hat{W}_{t}^{w} \leq\left(1-\hat{y}_{t}\right) W_{t}^{w, \max } & \forall t \in \mathcal{H} \\
P_{t}^{-}, P_{t}^{+} \geq 0 & \forall t \in \mathcal{H} \\
\hat{y}_{t} \in\{0,1\} & \forall t \in \mathcal{H}
\end{array}
$$

The duration of a period is given by $d t$ which for one quarter equals $0.25 \mathrm{~h}$. The amount of power bought from or sold to the grid in period $t, P_{t}^{+}$and $P_{t}^{-}$, respectively at the prices $\pi_{t}^{+}$and $\pi_{t}^{-}$in $€ / \mathrm{kWh}$, is determined from the heat pump consumption for space heating, $\hat{W}_{t}^{s}$, or domestic hot water heating, $\hat{W}_{t}^{w}$, and the power consumed or produced by other electric appliances $\Gamma_{t}$ in (2b). We assume $\pi_{t}^{+}>\pi_{t}^{-}$. The case of an equality can be handled by removing constraint (2b) and using $\hat{P}_{t}$ in the objective function. The fact that heat pumps cannot be used simultaneously for space heating and domestic hot water heating is modeled by a binary variable $\hat{y}_{t}$ equal to one if the heat pump is used for space heating and to zero for domestic hot water production.

In the following, the optimization problem to solve in order to obtain the potential maximum upward modulation in a period $\tau$ with a payback effect in $k$ following periods is detailed. The maximum modulation available in one house at a given period is denoted $\delta_{\tau}$, and, in the case of an upward modulation, is obtained by solving

$$
\max \delta_{\tau}-\epsilon I^{+}-\epsilon I^{-}
$$

subject to,

$$
\begin{array}{lr}
P_{t}=W_{t}^{s}+W_{t}^{w}+\Gamma_{t} & \forall t \in \mathcal{K}(\tau, k) \\
P_{t}=\hat{P}_{t}+\delta_{t} & \forall t \in \mathcal{K}(\tau, k) \\
0 \leq W_{t}^{s} \leq y_{t} W_{t}^{s, \max } & \forall t \in \mathcal{K}(\tau, k) \\
0 \leq W_{t}^{w} \leq\left(1-y_{t}\right) W_{t}^{w, \max } & \forall t \in \mathcal{K}(\tau, k) \\
-I^{-} \leq \delta_{t} \leq I^{+} & \forall t \in \mathcal{K}(\tau, k) \backslash\{\tau\} \\
I^{-}, I^{+} \geq 0 & \\
\mathbf{x}_{\tau}=\hat{\mathbf{x}}_{\tau} & \forall t \in \mathcal{K}(\tau, k) \\
\mathbf{x}_{t+1}=f\left(\mathbf{x}_{t}, W_{t}^{s}, W_{t}^{w}, \mathbf{u}_{\mathbf{t}}\right) & \forall t \in \mathcal{K}(\tau, k) \\
\mathbf{x}_{t}^{\text {min }} \leq \mathbf{x}_{t} \leq \mathbf{x}_{t}^{\text {max }} & \\
-\sigma \leq \hat{\mathbf{x}}_{\tau+k+1}-\mathbf{x}_{\tau+k+1} \leq \sigma &
\end{array}
$$

where $I^{+}$and $I^{-}$are the maximum positive and negative deviations with respect to the baseline on the payback horizon. These deviations are penalized by a parameter $\epsilon$ arbitrarily set in our tests to $10^{-2}$.

Equation (3c) defines the modulation that can be achieved in each house with respect to its baseline. The initial condition on the state is given by (3h). Equality (3k) ensures that the state at the end of the modulation horizon is close to the one given by the baseline. As the state transition only depends on the previous state and the power consumed by the heat pump, this condition ensures that there is no major deviations from the baseline after the payback horizon. The case of maximum downward modulation is obtained by replacing (3a) by

$$
\min \delta_{\tau}+\epsilon I^{+}+\epsilon I^{-}
$$

The total potential of modulation for the portfolio of an aggregator is obtained by summing the individual potential of each house.

\section{BUILDINGS AND HEAT PUMPS}

The heat demand from the buildings can be determined using models containing different levels of details. Greybox models are simplified models that provide an accurate representation of the thermal response of a building with reduced computational requirements [13]. The building thermal behavior is modeled by an equivalent thermal network consisting of thermal resistances, $R$ in $\mathrm{K} / \mathrm{W}$, and lumped thermal capacitances, $C$ in $\mathrm{J} / \mathrm{K}$. The $\mathrm{RC}$ parameters of the network are identified from validated models with higher level of details. For the purpose of this study, a single zone 5R3C structure, illustrated in Fig. 2 and presented in [12], is used. 


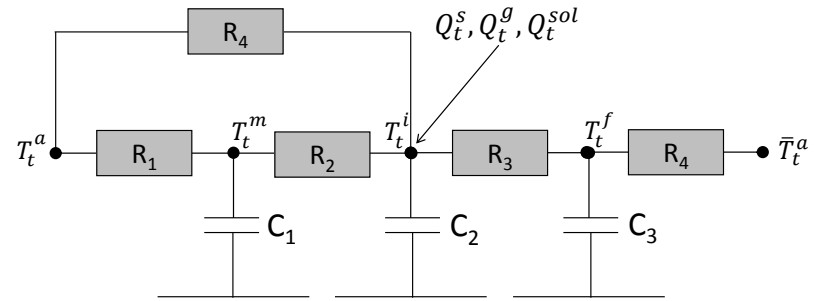

Figure 2: 5R3C Grey-box model structure

Such models allow a straightforward linear state-space formulation of the governing differential equations as follows

$$
\mathbf{x}_{t+1}^{s}=\mathbf{A}^{s} \mathbf{x}_{t}^{s}+\mathbf{B}^{s} \mathbf{u}_{t}^{s}+\mathbf{E}^{s} Q_{t}^{s}
$$

where $Q_{t}^{s}$ is the space heating thermal power in period $t$. The state vector $\mathbf{x}_{t+1}^{s}$ is a three-elements vector composed of the indoor air temperature, $T_{t}^{i}$, the wall mass temperature, $T_{t}^{m}$, and the floor temperature, $T_{t}^{f}$. $\mathbf{u}_{t}^{s}$ is a four-elements vector composed of the uncontrolled model inputs, i.e. the outdoor air temperature, $T_{t}^{a}$, the yearly average outdoor air temperature, $\bar{T}_{t}^{a}$, the solar gains, $Q_{t}^{s o l}$ and the internal gains due to occupants and appliances, $Q_{t}^{g}$. Matrices $\mathbf{A}^{s}, \mathbf{B}^{s}$ and $\mathbf{E}^{s}$ are equivalent $\mathrm{RC}$ parameters of the state-space model that are dependent on the house being modeled. The indoor thermal comfort of the occupants should be satisfied at any time as imposed by the constraint

$$
T_{t}^{\min } \leq T_{t}^{i} \leq T_{t}^{\max }
$$

The domestic hot water tank is modeled using a one-node capacitance model with homogeneous water temperature $\mathbf{x}_{t}^{w}$. Heat losses to the ambiance are considered. The energy conservation law can be expressed by the state-space formulation

$$
\mathbf{x}_{t+1}^{w}=\mathbf{A}^{w} T_{t}^{w}+\mathbf{B}^{w} \mathbf{u}_{t}^{w}+\mathbf{E}^{w} Q_{t}^{w}
$$

where $Q_{t}^{w}$ is the domestic hot water heating demand in period $t$ and $T_{t}^{w}$ is the water temperature in the tank constrained by

$$
T^{\min } \leq T_{t}^{w} \leq T^{\max }
$$

The input vector $\mathbf{u}_{t}^{w}$ is composed of the outdoor air temperature and the mains water temperature. The matrices $\mathbf{A}^{w}, \mathbf{B}^{w}$ and $\mathbf{E}^{w}$ are parameters of the state space model dependent on the house modeled.

Variable-speed air-to-water heat pumps are used to cover the domestic hot water and heating needs of the houses. They are modeled using a linear empirical model based on the ConsoClim method [14]. The same model is used for space heating and domestic hot water, and it only differs by the temperature of the water supplied to the house and that of the water tank, $T^{s u}$ in $\mathrm{K}$. The model determines the parameter $W_{t}^{\max }$ linked to the coefficient of performance (COP) of the heat pump, which is later used to obtain the relation between electrical power $W_{t}$ and heat demand $Q_{t}$.

$$
\begin{aligned}
& Q_{t}^{\max }=\left(d_{0}+d_{1}\left(T_{t}^{a}-T^{a, n}\right)+d_{2}\left(T_{t}^{s u}-T^{s u, n}\right)\right) Q^{n} \\
& \Delta T_{t}=\frac{T_{t}^{a}}{T_{t}^{s u}}-\frac{T^{a, n}}{T^{s u, n}} \\
& C O P_{t}^{\max }=\frac{C O P^{n}}{c_{0}+c_{1} \Delta T_{t}+c_{2} \Delta T_{t}^{2}} \\
& W_{t}^{\max }=\frac{Q_{t}^{\max }}{C O P_{t}^{\text {max }}}
\end{aligned}
$$

Equation (9a) determines the maximum thermal power that can be supplied by the heat pump for given ambient and water supply temperatures. The coefficient of performance is determined by Equation $(9 \mathrm{c})$ and the corresponding electrical consumption of the compressor is given by Equation (9d). The part-load electrical consumption of the variable-speed compressor, $W_{t}$ is expressed as a function of the heat demand, $Q_{t}$, using a piecewise linear approximation

$$
\begin{array}{rlrl}
W_{t} & =f_{1} \frac{Q_{t}}{Q_{t}^{\text {max }}} W_{t}^{\text {max }} & \text { for } \frac{Q_{t}}{Q_{t}^{\text {max }}} \leq 0.3 \\
W_{t}=f_{2} \frac{Q_{t}}{Q_{t}^{\text {max }}} W_{t}^{\text {max }} & \text { for } \frac{Q_{t}}{Q_{t}^{\text {max }}}>0.3
\end{array}
$$

Technical constraints prevent the heat pump from working simultaneously to supply heat to the domestic hot water tank and to the space heating system. To prevent the damage of mechanical components, decisions to start or stop the heat pumps should not occur more than eight times an hour. This precaution is ensured by a decision time step of 15 minutes.

The thermal states transition, given by Equations (5), (7) and (10), and the state constraints, given by Equations (6) and (8), are summarized by

$$
\begin{aligned}
& \mathbf{x}_{t+1}=f\left(\mathbf{x}_{t}, W_{t}^{s}, W_{t}^{w}, \mathbf{u}_{t}\right) \\
& \mathbf{x}_{t}^{\min } \leq \mathbf{x}_{t} \leq \mathbf{x}_{t}^{\max }
\end{aligned}
$$

where $\mathbf{x}_{t}=\left[\mathbf{x}_{t}^{s} T_{t}^{w}\right]$ and $\mathbf{u}_{t}=\left[\begin{array}{ll}\mathbf{u}_{t}^{s} & \mathbf{u}_{t}^{w}\end{array}\right]$.

\section{RESULTS}

\section{A. Generation of the test cases}

The methodology presented in the previous sections is applied to a case study composed of a hundred buildings representative of freestanding houses built after 1971 in Belgium. The geometry and envelope characteristics of the residential buildings come from study [15]. The average heat pump nominal power is $4.3 \mathrm{~kW}$. Nominal conditions are defined according to those in [16] for a $7^{\circ} \mathrm{C}$ outdoor temperature and a water temperature adapted to the house insulation level. Additional resistances of 3 to $5 \mathrm{~kW}$ depending on the house insulation level are used as backup to cover the heat demand for space heating during the coldest days of the year. The control horizon is set to 24 hours divided into 96 periods.

The number of inhabitants in each house is drawn from a normal distribution of average three and a standard deviation of two with a maximum of five occupants. The exogenous consumption profiles of lighting and appliances are obtained 
from article [17], as well as the domestic hot water draw-off events. Indoor temperature set point schedules are intermittent temperature profiles generated based on normal distribution laws for morning, midday and evening start-up times. All profiles have a weekly average indoor set point above $18^{\circ} \mathrm{C}$. Occupancy profiles are derived from the latter. The indoor thermal comfort of the occupants should be satisfied all times. During the heating season, the indoor air temperature is constrained to deviate a maximum of $1^{\circ} \mathrm{C}$ from the imposed set point during occupied periods of the daytime and from the extreme limits of the daily set point during the night. In the summer, the lower limit of the indoor air temperature is set to $1{ }^{\circ} \mathrm{C}$ below the imposed set point and the upper limit is set to $25^{\circ} \mathrm{C}$, since no cooling system is considered.

Buildings are equipped with conventional hydronic radiators. The temperature of the water supplied to the radiator is adjusted according to the insulation level of each building. The radiators are assumed to be sized so that they are able to supply the thermal power required by the building at any time and the dependency of the emitted heat on the water supply temperature is not modeled. The domestic hot water tank lower limit in (8) is imposed by sanitary constraints to $50^{\circ} \mathrm{C}$, whereas the upper limit of $65^{\circ} \mathrm{C}$ is imposed by the heat pump design. The tank volume is adapted for each house based on a water consumption of 50 liters per person per day, with an additional safety volume of 50 liters. It therefore comprises between 100 and 300 liters. The supply temperature is set to $65^{\circ} \mathrm{C}$ which underestimates the performance of the heat pump. The parameters of the heat pump model detailed in (9) and (10) are calibrated based on manufacturer data.

\section{B. Illustration with a single house}

Fig. 3 shows results for an upward modulation activated at time period 58 for a payback of four periods. A total electrical power consumption increase of $2.9 \mathrm{~kW}$ can be observed in Fig. 3a, which corresponds in this example to the upward activation of the heat pump power for space heating as illustrated in Fig. 3b. The $2.9 \mathrm{~kW}$ consumption increase at period 58 is directly followed by a decrease in electricity use for space heating in the next period. In order to minimize the amplitude of the power payback, and since the heat pump cannot work in both space heating and domestic hot water modes simultaneously, the diminution of power demand for space heating is counterbalanced by a shift of consumption for domestic hot water production from period 60 to 59 .

\section{Results on the aggregated portfolio}

The maximum upward and downward modulations for the aggregated portfolio of houses are illustrated in Fig. 4 for a winter weekday and three payback horizon lengths. The largest upward and downward modulations are obtained in periods 0 to 28 , with maximum amplitudes reaching $400 \mathrm{~kW}$ and 210 $\mathrm{kW}$ respectively. During that time frame, most of the flexibility is provided by space heating consumption. The temperature profiles present a night setback where the set point is reduced and the allowed temperature range is wider. Since during that

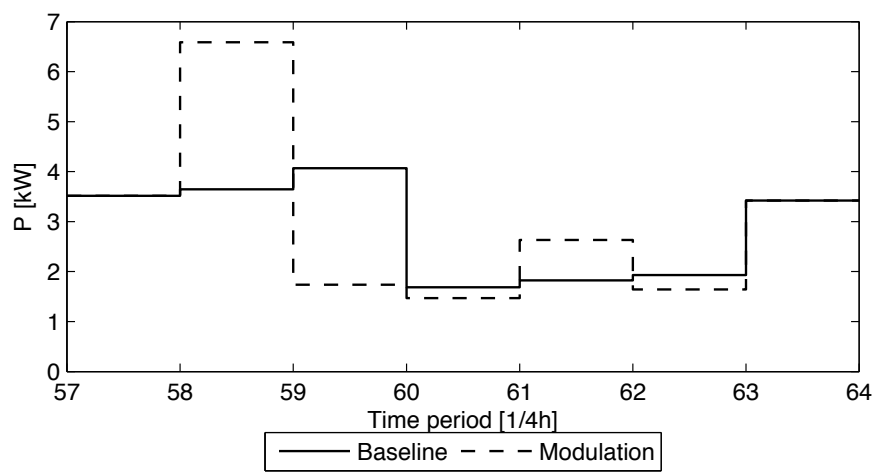

(a) Total power modulation.

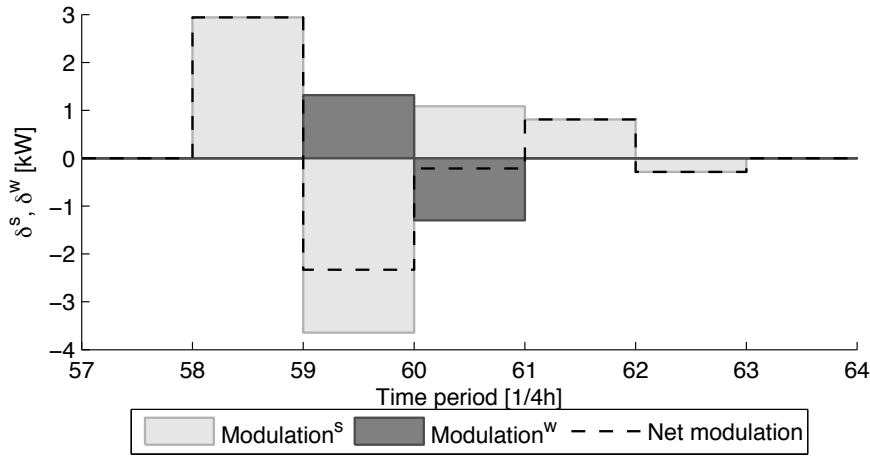

(b) Space heating and domestic hot water power modulation.

Figure 3: Power modulation of a 1980s freestanding house for activation in period 58 and with a payback of four periods.

period outdoor temperature variations and internal heat gains are limited, the upward and downward modulation amplitude are fairly constant. For the upward modulation, there is a maximum in periods 16 to 28 . This phenomenon is due to the higher room temperature set point for the daytime, which allows a faster return to the baseline electricity demand of the house. In the case of downward modulation, the limitation of the heat pump capacity reduces the achievable downward modulation as one gets closer to the set point transition. The upward peaks observed in periods 30 and 88 correspond to the start-up of heat pumps to produce domestic hot water after usual morning and evening water draw-off events. During the day, most of the upward and downward modulations are provided by space heating. Flexibility from the domestic hot water tank is mostly restricted by the high inertia of the water tanks, which is caused by their insulation. In addition to this inertia, major hot water draw-off events mainly happen in the morning and evening, which limits consumption needs. The heat pump is more often used for space heating as the deadband of the room temperature is set to only $2^{\circ} \mathrm{C}$ during the day. With the heat pump being limited to work in one mode at a time, consumption for domestic hot water is mostly concentrated in single periods to give more freedom for space heating. The potential of downward modulation gets close to zero for time periods between 88 and 95 . This is due to fact that the first optimization of the baseline drives the system toward minimizing the consumption, and therefore the temperatures hit their lower bound. 


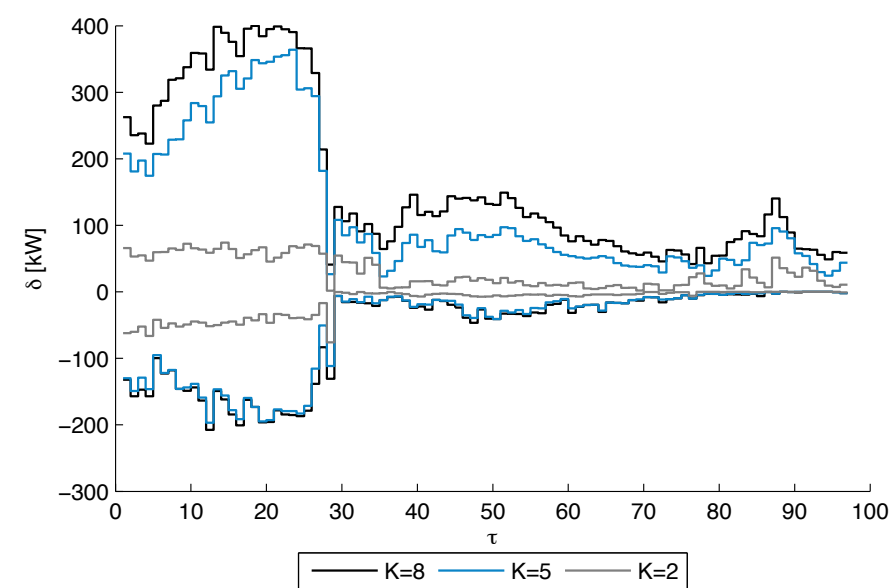

Figure 4: Influence of the payback length on the modulation for each activation period on January 24th for 100 houses.

Fig. 5 illustrates the seasonal modification of the flexibility potential on the 24th of January, April, June and November. The difference in modulation profiles observed between November and January lies in the higher outdoor temperature, which, combined to the nighttime setback reduces the flexibility potential for space heating for time periods below 20 . The relative share of electricity consumption devoted to domestic hot water production increases in warmer seasons.

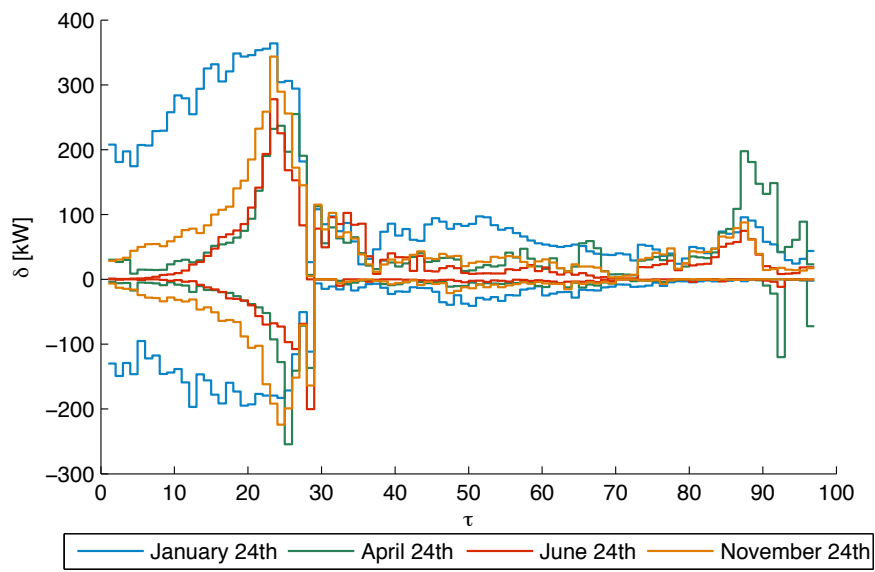

Figure 5: Seasonal influence on the modulation for each activation period on January 24th for 100 houses.

Tables Ia and Ib provide a detailed quantification of the cost, the overconsumption, and the deviation following the modulation, respectively, for the upward and downward activations on January 24th. The overconsumption is the net difference in energy consumed between the baseline consumption and the consumption with the modulation. The deviation is the sum of the absolute differences, during the payback periods, between the baseline consumption and the consumption after modulation. Allowing a payback time of one hour and 15 minutes leads to an average upward modulation of 1.2 $\mathrm{kW}$ per house with a deviation of $600 \mathrm{Wh}$, whereas the average downward modulation reaches $500 \mathrm{~W}$ per house with a deviation of $420 \mathrm{Wh}$. Several differences can be observed between upward and downward activations. First, the average downward modulation amplitude is smaller than the corresponding upward modulation. The reason comes from the choice of a cost-optimal baseline which drives the zone and water tank temperature trajectories closer to the lowest set points, particularly during peak price hours. Secondly, deviation from baseline consumption and overconsumption are proportionally larger for downward activations. In the case of an upward activation, the resulting higher temperature level entails an increase in heat losses to the ambiance, hence the overconsumption. For a downward activation, and if the payback time crosses a transition from a lower set point to a higher set point, the heat pump has to work closer to its maximum capacity and sometimes resort to the backup electrical resistance, which reduces its coefficient of performance and increases the payback consumption. A downward modulation of the electricity demand is therefore more expensive.

TABLE I: Influence of the payback length on modulations for January 24th, 2012, for 100 houses.

(a) Upward activations

\begin{tabular}{c|ccc|c|c|c}
\hline & \multicolumn{3}{|c|}{$\begin{array}{c}\text { Modulation } \\
{[\mathbf{k W}]}\end{array}$} & $\begin{array}{c}\text { Deviation } \\
{[\mathbf{k W h}]} \\
\text { mean }\end{array}$ & $\begin{array}{c}\text { Cost } \\
{[€]} \\
\text { mean }\end{array}$ & $\begin{array}{c}\text { Overconsumption } \\
{[\mathbf{k W h}]} \\
\text { mean }\end{array}$ \\
\hline \hline 1 & 0.0 & 4.9 & 48.0 & 1.1 & 0.2 & 0.1 \\
2 & 1.7 & 29.2 & 74.0 & 11.5 & 1.3 & 2.8 \\
3 & 7.0 & 70.1 & 206.1 & 35.0 & 3.8 & 8.7 \\
4 & 14.8 & 97.6 & 295.8 & 49.1 & 5.4 & 12.1 \\
5 & 23.1 & 121.3 & 364.0 & 59.8 & 6.7 & 14.7 \\
6 & 31.6 & 136.4 & 382.2 & 67.1 & 7.5 & 16.2 \\
7 & 37.5 & 149.4 & 396.4 & 74.2 & 8.3 & 17.7 \\
8 & 40.9 & 160.1 & 399.8 & 80.8 & 9.0 & 19.1
\end{tabular}

(b) Downward activations

\begin{tabular}{c|ccc|c|c|c}
\hline & \multicolumn{3}{|c|}{$\begin{array}{c}\text { Modulation } \\
{[\mathbf{k W}]}\end{array}$} & $\begin{array}{c}\text { Deviation } \\
{[\mathbf{k W h}]} \\
\text { mean }\end{array}$ & $\begin{array}{c}\text { Cost } \\
{[€]} \\
\text { mean }\end{array}$ & $\begin{array}{c}\text { Overconsumption } \\
{[\mathbf{k W h}]} \\
\text { mean }\end{array}$ \\
\hline \hline 1 & 0.0 & 0.9 & 61.6 & 0.2 & 0.0 & 0.0 \\
2 & 0.0 & 15.4 & 75.9 & 11.0 & 1.0 & 2.7 \\
3 & 0.0 & 38.4 & 138.7 & 35.8 & 3.3 & 8.4 \\
4 & 0.0 & 48.3 & 178.1 & 39.5 & 3.8 & 9.5 \\
5 & 0.0 & 53.5 & 196.9 & 42.4 & 4.1 & 10.3 \\
6 & 0.0 & 55.1 & 197.9 & 43.0 & 4.3 & 10.5 \\
7 & 0.0 & 56.3 & 203.7 & 44.1 & 4.4 & 10.7 \\
8 & 0.0 & 56.9 & 207.5 & 44.0 & 4.4 & 10.7
\end{tabular}

Table II presents the seasonal variation of the mean values for a payback of five periods. Results show that it is possible to harvest an average upward modulation of $400 \mathrm{~W}$ to $1.2 \mathrm{k} \mathrm{W}$ per house with a payback of $150 \mathrm{Wh}$ to $600 \mathrm{Wh}$, or a downward modulation of $100 \mathrm{~W}$ to $500 \mathrm{~W}$ per house with a payback of $60 \mathrm{Wh}$ to $420 \mathrm{Wh}$. The overconsumption varies between $60 \mathrm{Wh}$ and $150 \mathrm{Wh}$ per house for an upward activation and between $40 \mathrm{Wh}$ and $100 \mathrm{Wh}$ for a downward activation.

TABLE II: Seasonal variation of modulations amplitude for 100 houses in the year 2012 .

\begin{tabular}{c|cc|cc|cc}
\hline & \multicolumn{2}{|c|}{$\begin{array}{c}\text { Modulation } \\
{[\mathbf{k W ]}}\end{array}$} & \multicolumn{2}{c|}{$\begin{array}{c}\text { Deviation } \\
{[\mathbf{k W h}]}\end{array}$} & \multicolumn{2}{c}{$\begin{array}{c}\text { Overconsumption } \\
{[\mathbf{k W h}]}\end{array}$} \\
& upward & downward & upward & downward & upward & downward \\
\hline \hline Jan. & 121.3 & 53.5 & 59.8 & 42.4 & 14.7 & 10.3 \\
Apr. & 54.9 & 17.7 & 25.7 & 9.7 & 4.2 & 1.8 \\
Jun. & 37.9 & 10.9 & 15.4 & 6.2 & 2.4 & 1.1 \\
Nov. & 58.7 & 24.7 & 29.4 & 16.0 & 5.9 & 3.6
\end{tabular}




\section{CONCLUSION}

This paper presents a flexibility service provided by a load aggregator controlling domestic heat pumps. The heat pumps are used to supply both domestic hot water production and space heating needs. The flexibility service consists of the upward or downward activation of heat pumps at a certain time period with a payback effect over a fixed number of periods. A sequential optimization scheme is proposed to determine the maximum modulation amplitude from an optimized baseline for different payback durations. The methodology is applied to a case study composed of a hundred freestanding houses representative of the Belgian residential building stock and built after 1971. Simulation results indicate that an average modulation amplitude of $400 \mathrm{~W}$ to $1.2 \mathrm{~kW}$ per house, depending on the season, can be obtained in the case of an upward activation. In the case of a downward activation, the average value per house lies between $100 \mathrm{~W}$ and 500 W. About $80 \%$ of the flexibility potential comes from the modulation of the heat pump power in space heating mode in the winter, whereas the potentials relative to space heating and domestic hot water production tend to even out in the mid-season. Overconsumption varies between $60 \mathrm{Wh}$ and 150 Wh per house for an upward activation and between $40 \mathrm{Wh}$ and $100 \mathrm{Wh}$ per house for a downward activation. For future work, other modulation services may be proposed to tackle scenarios prompted by different grid management constraints. Extending the modulation on more than one period could be considered. This would make the computations more technical as the problem could no longer be decomposed per heat pump. The consequences of simultaneously optimizing the baselines and the flexibility services should be investigated. Finally, the level of detail for the buildings and system models could be increased to include non-linear behaviors.

\section{REFERENCES}

[1] S. Mathieu, Q. Louveaux, D. Ernst, and B. Cornélusse, "Dsima: A testbed for the quantitative analysis of interaction models within distribution networks," Sustainable Energy, Grids and Networks, vol. 5, pp. 78 -93, 2016, ISSN: 2352-4677.

[2] S. Mathieu, D. Ernst, and Q. Louveaux, "An efficient algorithm for the provision of a day-ahead modulation service by a load aggregator," in Innovative Smart Grid Technologies Europe, IEEE/PES, 2013.

[3] S. Mathieu, Q. Louveaux, D. Ernst, and B. Cornélusse, "A quantitative analysis of the effect of flexible loads on reserve markets," in Proceedings of the 18th Power Systems Computation Conference, IEEE, 2014.

[4] S. Koch, J. L. Mathieu, and D. S. Callaway, "Modeling and control of aggregated heterogeneous thermostatically controlled loads for ancillary services," in Proceedings of the 17th Power Systems Computation Conference, 2011.

[5] D. Patteeuw and L. Helsen, "Residential buildings with heat pumps, a verified bottom-up model for demand side management studies," Status: Published, 2014.
[6] A Molina, A Gabaldon, J. Fuentes, and C Alvarez, "Implementation and assessment of physically based electrical load models: Application to direct load control residential programmes," IEEE ProceedingsGeneration, Transmission and Distribution, vol. 150, no. 1, pp. 61-66, 2003.

[7] G. S. Pavlak, G. P. Henze, and V. J. Cushing, "Optimizing commercial building participation in energy and ancillary service markets," Energy and Buildings, vol. 81, pp. 115-126, 2014.

[8] — "Evaluating synergistic effect of optimally controlling commercial building thermal mass portfolios," Energy, 2015.

[9] R. De Coninck and L. Helsen, "Bottom-up quantification of the flexibility potential of buildings," in Building simulation, 13th international conference of the international building performance simulation association, IBPSA, Aix-les-Bains, France, 2013.

[10] M. Ali, A. Alahäivälä, F. Malik, M. Humayun, A. Safdarian, and M. Lehtonen, "A market-oriented hierarchical framework for residential demand response," International Journal of Electrical Power \& Energy Systems, vol. 69, pp. 257-263, 2015.

[11] M. Goldberg, "Measure twice, cut once," Power and Energy Magazine, IEEE, vol. 8, no. 3, pp. 46-54, 2010.

[12] G. Masy, E. Georges, C. Verhelst, V. Lemort, and P. André, "Smart grid energy flexible buildings through the use of heat pumps and building thermal mass as energy storage in the belgian context," Science and Technology for the Built Environment, vol. 21, no. 6, pp. 800-811, 2015.

[13] F. Déqué, F. Ollivier, and A. Poblador, "Grey boxes used to represent buildings with a minimum number of geometric and thermal parameters," Energy and Buildings, vol. 31, no. 1, pp. 29 -35, 2000.

[14] A. Bolher, R. Casari, E. Fleury, D. Marchio, and M. J., "Méthode de calcul des consommations d'énergie des bâtiments climatisés ConsoClim," Ecole des Mines (Paris), Tech. Rep., 1999.

[15] S. Gendebien, E. Georges, S. Bertagnolio, and V. Lemort, "Methodology to characterize a residential building stock using a bottom-up approach: A case study applied to belgium," International Journal of Sustainable Energy Planning and Management, vol. 4, pp. 71-88, 2015.

[16] Bureau of standardization, "EN14511 - 2 (2008) : Air conditioners, liquid chilling packages and heat pumps with electrically driven compressors for space heating and cooling - part 2: Test conditions," European Standard, 2007.

[17] E. Georges, S. Gendebien, S. Bertagnolio, and V. Lemort, "Modeling and simulation of the domestic energy use in belgium following a bottom-up approach," in CLIMA 2013 11th REHVA World Congress \& 8th International Conference on IAQVEC, 2013. 